\title{
Kolokyum Raporu:
}

\section{"Aktuelle Perspektiven der Deutsch-Türkischen und Interkulturellen Germanistik" \\ 25.06.2021-02.07.2021}

\section{Colloquium Report:}

"Contemporary Perspectives on Turkish-German and International German Studies"

25.06.2021-02.07.2021

Serra YILMAZ 10

'Araştırma Görevlisi, İstanbul Üniversitesi, Edebiyat Fakültesi, Batı Dilleri ve Edebiyatları Bölümü, Alman Dili ve Edebiyatı Anabilim Dalı, İstanbul, Türkiye ORCID: S.Y. 0000-0001-5791-2842

\section{Corresponding author:}

Serra YILMAZ,

İstanbul Üniversitesi, Edebiyat Fakültesi, Batı Dilleri ve Edebiyatları Bölümü, Alman Dili ve Edebiyatı Anabilim Dalı, Balbanağa Mah. Ordu Cad. No:6, Laleli, Fatih, İstanbul, Türkiye

E-mail: serra.yilmaz@istanbul.edu.tr

Submitted: 07.09.2021

Accepted: 20.07.2021

Citation: Yilmaz, S. (2021, Haziran-Temmuz). Kolokyum raporu: "Aktuelle perspektiven der Deutsch-Türkischen und interkulturellen Germanistik" "Türk-Alman ve uluslararası Germanistik çalışmalarında güncel perspektifler". Alman Dili ve Edebiyatı Dergisi - Studien zur deutschen Sprache und Literatur, 46, 169-179. https://doi.org/10.26650/sdsl2021-992235 
Alman Akademik Değişim Servisi'nin (DAAD) destekleyicisi olduğu İstanbul Üniversitesi, Marmara Üniversitesi, Ege Üniversitesi ve Paderborn Üniversitesi'nin katılımlarıyla yürütülen Alman Dili ve Edebiyatı Bölümleri Arasında İşbirliği Projesi (GIP) kapsamında "Interkulturelle Perspektiven der deutschsprachigen Gegenwartskultur" başlığı altında düzenlenen "Aktuelle Perspektiven der Deutsch-Türkischen und Interkulturellen Germanistik im Rahmen der Germanistischen Institutspartnerschaft Pader-Ege-Bosporus" adlı kolokyum, projeye katkı sağlayan üniversitelerden öğretim üyelerinin, lisansüstü öğrencilerin ve bu alanda çalışmalar yapan davetlilerin katılımlarıyla çevrimiçi olarak gerçekleştirildi. İki gün süren programın "Interkulturelle Perspektiven des Deutsch-Türkischen Films" adını taşıyan ilk bölümü 25.06.2021 tarihinde, "Aktuelle Beiträge zur Forschung" adlı ikinci bölümü ise 02.07.2021 tarihinde yapıldı. Kolokyumun amacı kültürlerarası bir bakış açısı ile Türk-Alman sineması, 'Fluchtliteratur'1, göç ve göçmen edebiyatı alanlarında çalışmalar yapan akademisyenleri, lisansüstü öğrencileri ve disiplinlerarası alanlarda önemli projeler yürüten araştırmacıları bir araya getirerek etkileşimde bulunmalarını ve fikir alışverişini sağlamaktı. Kolokyumda dokuz farklı üniversiteden çok sayıda araştırmacı dilbilim, edebiyatbilim ve kültürbilim alanlarında bildirilerini, incelemelerini ve projelerini sundular.

İlk gün Paderborn Üniversitesi Alman Dili ve Edebiyatı Enstitüsü öğretim üyesi Prof. Dr. Michael Hofmann'ın açılış konuşması ile başladı. Hofmann'ın açılış konuşmasından sonra gerçekleştirdiği "Migrationskino als Weltkino Genre-Perspektiven auf Filme Fatih Akıns" başıkılı sunumu Fatih Akın'ın en çok bilinen dört yapıtı olan Im Juli (2000), Gegen die Wand (2004), Auf der anderen Seite (2007) ve Soul Kitchen (2009) filmlerinin incelemesi üzerineydi. Bu filmleri biçim, biçem ve tür bakımından ele alan Hofmann, göç ve göç sonrası olguların bu eserlerde nasıl ortaya çıktığı ve bu olguların filmlerin türleriyle nasıl ilişkilendirildiği konularına odaklandı. Hofmann konuşmasına "Gattung" ve "Genre" terimlerinin film çalışmaları ve edebiyatbilim alanlarındaki tanımlarından bahsederek başladı. Daha sonra Fatih Akın'ın yukarıda belirtilen filmlerinin "Roadmovie", "Melodram", "Episodenfilm", "Culture-Clash-Komödie", "Western" ve "Gerichtsfilm" türleri bağlamında incelenebileceğinin üzerinde durdu.

Sunumun ilerleyen bölümlerinde Hofmann "Weltliteratur" (Dünya Edebiyatı) ve "Weltkino" (Dünya Sineması) kavramlarını ele aldı. Öncelikle "Weltliteratur"u betimleyen

1 Türkçeye birebir çevrildiğinde "kaçış edebiyatı" olarak karşılık bulan bu kavram Alman edebiyatında ülkelerinden savaş, terör, doğal afetler veya yaşamlarını tehdit eden başka bir durum sebebiyle kaçmak zorunda kalan yazarların, kaçışın nedenlerini, sürecini ve etkilerini konu alan eserlerini içeren bir edebiyat türüne verilen addır. 
Hofmann, söz konusu terimin edebiyat dünyasına Goethe tarafından kazandıııldığını vurguladı. "Weltkino" gibi bir kavramın ise edebiyatla yakın bir ilişki içinde olan sinema sanatı için söz konusu olamayacağını, çünkü sinema olgusunun konsept itibarıyla zaten uluslararası nitelikte olduğunu belirtti. Bu bağlamda Fatih Akın'ın filmleri için sadece "Türk-Alman filmi" tanımlaması yapılmasının indirgeyici bir yaklaşım olacağına dikkat çekti. Dolayısıyla "Genre" yani tür bağlamında yapılan analizlerin Türk-Alman sinemasının uluslararası olma özelliğini ön plana çıkaracağına işaret etti. Hofmann sonrasında Fatih Akın'ın Im Juli adlı filmini türü bakımından inceleyerek filmin "Roadmovie" kategorisinde yer aldığı ve bu açıdan içinde kültürlerarası bileşenler barındırdığını dile getirdi. Sunumda incelenen bir sonraki film olan Gegen die Wand ise Hofmann tarafından tür olarak "Melodram" şeklinde sınıflandırıldı. Fatih Akın'ın diğer bir yapıtı olan Auf der anderen Seite sunumun devamında kısaca ele alındı. Araştırmacının "Episodenfilm" kategorisine dahil ettiği bu eserin Meksikalı yönetmen Alejandro G. Iñárritu'nun Babel (2006) adlı filmiyle tür bağlamında benzer olduğuna değinildi. Hofmann incelediği bir diğer eser olan 2009 yapımı Soul Kitchen filminin "Culture-Clash-Komödie" ve "Gangsterfilm" türlerinden unsurlar barındırdığına dikkat çekti. Film bu bağlamda My Big Fat Greek Wedding (2002) gibi yapımlarla aynı sınıfta konumlandırıldı. Ayrıca "Gangsterfilm" türünün göç olgusu bağlamında kullanılmasının göçmenlerin düştükleri zor durumları daha iyi göstermeye imkân sağladığı belirtildi. Sonuç olarak Hofmann, film türü özelindeki bakış açılarının Fatih Akın'ın eserlerinin kültürlerarası bağlantılarını öne çıkardığını ayrıca bu bakış açılarının Türk-Alman filmlerinin "yerelleştirilme"sinin önüne geçtiğini ifade etti.

Hofmann'ın bildirisinden sonra "Thematische Annäherung" başlıklı oturuma geçildi. Bu bölümündeki ilk konuşmacı Magdeburg Üniversitesi'nden Martina Kofer, "Noch immer kein Raum zum Atmen? Türkische Frauenfiguren im gegenwärtigen deutsch-türkischen Film" adlı çalışmasını tanıttı. Kofer sunumunda Türk kadınının Türk-Alman sinemasında kurban rolünde betimlenmesi ve Edward Said'in şarkiyatçılık tezi bağlamında modern Batı́nın bir karşıtı olarak sahneye konulması konularını ele aldı. Batı söyleminde TürkMüslüman kadının öznelleştirilmesi sürecini üç gruba ayıran Kofer, öncelikle 19. yüzyıldaki "Şarkiyatçılık ve Toplumsal Cinsiyet" söylemlerine değindi bu dönemde öne çıkan imgelere örnek olarak harem, kölelik ve egzotikleştirme gibi kavramları dile getirdi. Sonrasında 1970-80li yıllarda oluşan "Üçüncü Dünya” ve "Işçi Göçü" konuları üzerinde durdu ve buradaki temel olgular olarak ataerkil baskı, haksızıı, kurbanlaştırmaya değindi. Konuşmasına 2000li yıllarda ortaya çıkan İslam-Uyum Söylemi ile devam eden Kofer, güncel baskın imajlar olan uyum sorunu, dini baskı, kadın köle, eğitimsizlik gibi konuların altını çizdi. Sunumun devamında Neo-Orientalismus (Yeni-Şarkiyatçılık) söylemine 
odaklanarak bu söylemin 2000 yılından günümüze gelişimini irdeledi. Bu bağlamda "Doğu" algısının "Batı" nezdinde özellikle 11 Eylül saldırılarından sonra "Tehditkâr Doğu" şeklinde evirildiğini ve bunun "Öncü Kültür" ve "Farklı Kültür" şeklinde bir ikiliğe yol açtığını ifade etti. Sunumda "Öncü Kültür" e ait kadınların bağımsız olması ve bunun da "Batı Kültürü" için bir nitelik ve statü göstergesi olduğunun vurgulanması ilgi çekici bir ayrıntı olarak karşımıza çıktı. Daha sonra katılımcılara klasik Türk aile yapısına, Türk kadınına ve genel olarak Türk kültürüne ait olumsuz birçok klişe içeren Feo Aladağ'ın Die Fremde (2010) ve Buket Alakuş'un Einmal Hans mit scharfer Soße (2013) filmlerinin tanıtımlarından birer bölüm izletildi. Kofer, adı geçen yapıtlardaki Müslüman-Türk kültürü betimlemeleri üzerinde durdu ve bu sinema eserleri ile 2000'li yıllardaki namus cinayeti, zorla evlendirme gibi konuları işleyen edebiyat eserleri arasında koşutluklar bulunduğuna işaret etti. Araştırmacı buna ek olarak, Ömer Alkın'ın Türk-Alman sinema eserlerinde kadın figürlerinin betimlemesi konusunda bir dönüm noktasında bulunmadığımız, aksine bitmek bilmeyen bir kısır döngüde sıkışıp kaldığımız şeklindeki görüşlere katıldığını da dile getirdi. Kofer sunumunun sonunda bu tarz Türk-Alman komedi filmlerinde her zaman kuşak çatışması teması üzerinde durulduğunun ve kadın figürlerin eş, kız evlat ve anne rolünden öteye geçemediğinin altını çizdi.

Ege Üniversitesi Alman Dili ve Edebiyatı Bölüm Başkanı Doç. Dr. Saniye Uysal-Ünalan bu oturumun ikinci konuşmacısıydı. Uysal-Ünalan, "Kulturelle Differenz und Stereotypen in der türkisch-deutschen Filmkomödie" adlı sunumuna iki temel araştırma sorusuyla başladı: "Türk kültürü hakkındaki stereotipler ve kültür farkı Türk-Alman komedi filmlerinde nasıl sahneye konulur ve nasıl temsil edilir?" ve "Bu kültürel farklılıklar ve klişelerin göç sonrası uyum süreci konusundaki toplumsal söylemler ve dinamikler ile nasıl bir ilgisi vardır?". Sunumun devamında Türk-Alman komedi filmlerinin önemli unsurlarına değinilerek, bu tür filmlerin genellikle "Culture-Clash-Komödie" türünde yapıtlar olduğundan ve farklı kültürlerle karşılaşma sonucu oluşan aile içi çatışmaların konu olarak sık sık karşımıza çıktığından bahsedildi. Bu tür yapıtlarda sahnelenen kültürlerarası basmakalıp varsayımlara dayanan klişeler ve gerçekte olanlar arasındaki farkın sakıncalı bir durum yarattığına işaret eden Uysal-Ünalan, bu muğlak durumun daha ayrıntılı incelenmesi gerektiğini düşündüğünü dile getirdi. Ardından Wellgraf'dan bir alıntı yaparak medyanın göçmenler hakkındaki gerçeklik algısı inşası ile insanların kafasında oluşan imajlara değindi. Bu tür filmlerde toplumsal cinsiyet olgularının ve kadın figürlerinin ortaya çıkış şekillerinin önemine dikkat çeken Uysal-Ünalan, konuşmasının sonunda katılımcılara Christoph Schnee'nin Kückückskind (2013) adlı filminden bir bölüm izletti. Katılımcılar bu bölümü izledikten sonra Uysal-Ünalan Kückückskind adlı sinema 
eseri hakkında bilgi verdi. Böylece filmde sunumun başında bahsedilen kültürel farklılıkların ve medyanın ürettiği gerçeklik algılarından doğan klişelerin (örneğin kadın figürünün kurbanlaştırılması ve sessizliği, göçmenlerin ataerkil aile yapısı gibi) nasıl oluşturulduğu ve farklı yapıtlar üzerinden doğrulandığı görüldü.

Kolokyumun üçüncü oturumu Farah Bouamar ve Nabila Bushra'nın "LOST und I CAN HEAL YOU Genre und Kritik- über den Anspruch gendersensibel und rassimuskritisch Horror(kurz)filme zu produzieren" adlı sunumları ile başladı. Bu bölümde Farah Bouamar ve Nabila Bushra kendi projeleri olan ilk kısa filmlerini tanıtıp korku filmlerindeki yabancılaştırma temasını ele aldılar. Kısa filmlerinin gösteriminden sonra katılımcılar film ile ilgili izlenimlerini dile getirdiler. Kısa filmin odak noktasında yer alan şeytani kadın imgesi, kadın figürünün yabancılaştırılması temasını vurgulaması açısından dikkat çekiciydi.

Boumar ve Bushra'nın ilgi çekici kısa filmlerinden sonra, Paderborn Üniversitesi'nden Prof. Dr. Rita Morrien "Film und Gender - Nur eine Frau \& Aus dem Nichts (Weibliche Opferund Täterschaft)" adlı bildirisini sundu. Bildirisinde cinayete kurban giden Türk kökenli bir kadının kendi hikayesini anlattığı Nur eine Frau (2019) adlı sinema eserini ele alan Morrien, öncelikle filmin konusunun namus cinayeti değil kadın cinayeti olduğunun altını çizdi. Ayrıca üzerinde çokça tartışıldığı üzere "namus cinayeti" kavramının oldukça uygunsuz olduğunu bu yüzden kullanılmaması gerektiğini belirtti. Morrien konuşmasına artık geleneksel diyebileceğimiz "mağdur kadın", "fail erkek" olgularının gerçek hayatta yansımalarının sadece İslam kültüründe değil Batı kültüründe de görüldüğünü vurgulayarak devam etti. Ayrıca filmdeki erkeklerin oldukça baskın karakterler olarak betimlendiğini dile getiren Morrien, erkek figürlerin "hegemonik erillik" kavramının temsilcileri olarak sunulduğuna dikkat çekti. Morrien, öldürülen bir kadının sesi olan bu filmin sadece toplumsal cinsiyet kuramı değil aynı zamanda feminizm bağlamında da önemli mesajlar taşıdığına işaret etti.

Daha sonra Dortmund Teknik Üniversitesi'nden Sarah Reininghaus'un "Fatih Akıns Aus dem Nichts (2017) als Vertreter des türkisch-deutschen Films der 2010er Jahre mit einem vergleichenden Exkurs zu Hormanns Nur eine Frau (2019)" başlığını taşıyan sunumuna geçildi. Reininghaus çalışmasında, Fatih Akın'ın "Nationalsozialistischer Untergrund" adlı Almanya'da faaliyet gösteren aşırı sağcı ve ırkçı silahlı grubun bir Türk'ü ve oğlunu öldürmesini konu alan Aus dem Nichts (2017) isimli filmi ile yine Almanya'da öldürülen Türk-Alman bir kadının hikayesini anlatan Sherry Hormann'ın Nur eine Frau (2019) adlı 
sinema eserini karşılaştırmalı olarak inceledi. Bu incelemede Aus dem Nichts filmine ağırlık veren Reininghaus, filmde Nur eine Frau yapımına benzer bir şekilde Türk-Alman karakterin kurban rolünde olduğundan bahsetti. Ancak Aus dem Nichts eserinde -Nur eine Frau filminden farklı olarak- klişeleşmiş tipik Türk-Alman tasvirlerinin kullanılmamış olması bu noktada dikkat çekiciydi. Daha sonra Aus dem Nichts filmine dair eleştirileri değerlendiren Reininghaus, eleştirilerin yoğun olarak Türk göçmenlerin öldürülmesini konu edinen filmde baş karakterin bir Alman olarak seçilmesine yönelik olduğunu dile getirdi. Araştırmacı bu konu ile ilgili olarak Hannah Pilarczyk adlı eleştirmenin Der Spiegel'de yayınlanan bir metninden alıntı yaptı. Alıntıda Pilarczyk, nasyonal sosyalist yeraltı örgütünün bir kurbanının hikayesini sarışın bir Alman üzerinden anlatmanın siyahi insanların hikayesini beyaz bir ana figür üzerinden anlatan Hollywood filmlerindeki stratejiye benzer olduğunu belirttiği görüldü. Özet olarak Reininghaus, filme gelen tepkilerde kimlik, aitlik ve yabancılık üzerine sorular barındıran söylemlerin kendini gösterdiğini ifade etti.

Reininghaus'un sunumundan sonra sözü devralan Dortmund Üniversitesi'nden Dr. Hilal Keskin, "Vom anatolischen Heimatfilm zur modernen Familiengeschichte. Die Darstellung der deutsch-türkischen Kultur in Almanya -Willkommen in Deutschland" adlı bildirisine geçildi. Keskin ilk olarak "Gastarbeiterlnnengeneration" (misafir işçi jenerasyonu) konusunu işleyen filmlerde göçmenlerin genellikle toplum tarafından dışlanmış mağdur kişiler olarak gösterildiğini ve Türklerin de sessiz figürler olarak betimlendiğine değindi. Buna karşın Almanya - Willkommen in Deutschland (2011) filminde Türk karakterlerin alışılmış Türk ve göçmen stereotiplerinin dışında betimlendiğini belirten Keskin, bu durumun Türk-Alman sinemasında açıkça bir gelişim olarak gözlemlenebileceğini ekledi. Araştırmacı konuşmasının devamında Türk-Alman sinemasında ve edebiyatında önem teşkil eden "Interkulturalität" (kültürlerarasılık) kavramını "kültürlerarası etkileşim" şeklinde tanımladı ve kültürlerin kendine has özelliklerinin ancak başka kültürlerle etkileşime girildiğinde ortaya çıktığı vurguladı. Keskin bu noktada "kültürlerarasılık" bağlamında öne çıkan "Hybridität" (melezlik) kavramına da değindi. Kültürlerarası etkileşimin gerçekleştiği noktada ortaya çıkan "kültürel melezlik" unsurunu sadece kültürel unsurların harmanlanması olarak tanımlamanın yetersiz kalacağını dile getiren Keskin, bu kavramı iki kültürden de izler ve farklılıklar taşıyan yeni ve farklı bir olgu şeklinde adlandırdı. Keskin Almanya: Willkommen in Deutschland filminde yabancı olmanın zorluklarının inkâr edilmediğinin, ancak alışılanın aksine ön planda bir asimilasyonun değil, Yılmaz ailesinin kurduğu kültürel köprülerin görüldüğünü söyledi. Bu kültürel köprülere örnek olarak ise Yılmaz ailesinin 
Türk deyimlerini kelimesi kelimesine Almancaya çevirerek kullanmasını gösterdi. Sunumunun sonunda Keskin, söz konusu sinema eserinin ölüm, kültür, aile, kendini bulma gibi evrensel konulara temas ettiğini belirterek bu açıdan bu tür yapıtların göçmen filmleri olarak değil, bağımsız sanat yapıtları olarak nitelendirilmesinin kültürel algımıza katkıda bulunacağının altını çizdi.

İlk günün kapanışında Alman yazar ve gazeteci Angelika Overath bir okuma etkinliği gerçekleştirdi. Ein Winter in Istanbul (2018) adlı kitabından bölümler okuyan yazar, sonrasında katılımcıların sorularını yanıtladı.

Kolokyumun ikinci günü Prof. Dr. Michael Hofmann'ın açılış konuşmasıyla başladı. GIP (Germanistische Institutspartnerschaft) bünyesinde Paderborn Üniversitesi, Marmara Üniversitesi, Ege Üniversitesi ve İstanbul Üniversitesi akademik kadro ve öğrencilerinin ortak çalışması ile oluşturulması planlanan Handbuch zum Deutsch-Türkischen Film (TürkAlman Sineması Antolojisi) hakkında bilgi veren ve konferansın bir önceki oturumunun kısa bir özetini yapan Hofmann, ikinci günün sunumlarını kısaca tanıttıktan sonra sözü ilk konuşmacıya devretti.

"Aktuelle Projekte" başıılı ilk oturumda araştırmacılar ekipleriyle yürüttükleri bilimsel projeleri tanıttılar. İlk olarak Paderborn Üniversitesi'nde yürütülen “Informationssystem Graffiti in Deutschland (INGRID)" adlı projede araştırma görevlisi olarak çalışan Sven Niemann oldukça ilgi çekici olan projeleri hakkında bilgi verdi. Niemann projeyi hayata geçirmek için bir veri tabanına ihtiyaç duyduklarını, bu yüzden bilişim alanından yardım aldıklarını ve bu bağlamda projenin disiplinlerarası bir proje olarak nitelendirildiğini vurgulayarak söze başladı. Niemann tanıttığı projenin veri tabanında her türlü araştırma için çok sayıda değişik konu başlığı altında toplanmış 73 bin grafiti fotoğrafı bulunduğunu, bunların tamamının imgelem, betimleme biçimi, dili, yazım biçimi ve bağlam gibi temel yönlerinin göz önüne alınarak kaydedildiğini, elde edilen verilerin nitel ve nicel araştırmalar için kullanıma hazır olduklarını belirtti. Sunumun devamında Niemann "urban art" olarak da adlandırılan şehir sanatı grafitinin nasıl okunduğu ve nasıl anlamlandırıldığı hakkında bilgi verdi. Bir dilbilimci olarak bu metin türündeki dilsel yapılar ile ilgilendiğini vurgulayan Niemann, grafitilerin de doğal diller gibi kendilerine ait karakteristik özellikler barındırdığını ve belirli kurallar çerçevesindeki bu özellikleri gözlemleyerek nerede yazıldığının, ne anlattığının ve kime ya da neye ithaf edildiğinin çözümlenebilir olduğunu ifade etti. Proje katılımcılar tarafından büyük ilgi gördü. Sunum sonrasında konu hakkında fikirlerini belirten bazı katılımcılar, grafitilerin arkasındaki 
anlamın toplumun sosyal yapısı hakkında fikirler verebileceğini ve bunun ayrı bir araştırma konusu olabileceğini, böyle bir araştırma söz konusu olursa INGRID veri tabanından yardım alınabileceğini dile getirdiler.

Illk oturumun ikinci konuşmacısı olan Paderborn Üniversitesi'nden Dr. Friedrich Markewitz Deutsche Forschungsgemeinschaft (DFG) tarafından desteklenen "Soldaten! So darf es nicht weitergehen: Heterogene Widerstandskulturen - Sprachliche Praktiken des Sich-Widersetzens von 1933 und 1945" adlı projesini tanıttı. Markewitz bu projede isyan ve direniş temasını işleyen metinlerde hangi dil kullanım şekilleri bulunduğunun ve bunların metnin genel amacına ne ölçüde katkı sağladığının araştıııldığını belirtti. Nasyonal-Sosyalist rejime karşı direncin dilbilimsel yansımalarının önem teşkil ettiği proje kapsamında oluşturulan koleksiyonda 1933-1945 arasında oluşmuş belgeler, edebi metinler, günlük, muhtıra gibi özel ya da resmi metinlerin yanı sıra Almanya'da 1940-43 yılları arasında etkili olmuş "Weiße Rose” adlı direniş grubunun el ilanları ile hiç bilinmeyen yazılar, mektuplar ve o dönemi yaşamış görgü tanıklarına ait kişisel günlüklerin de yer aldığı ve bu metinlerin proje kapsamındaki dilbilimsel araştırmaların temelini oluşturduğu ifade edildi. Markewitz ayrıca proje kapsamında 2018 yılında bir antoloji kitabı basıldığını da kaydetti

"Aus der Forschung" adlı ikinci oturumda konuşmacılar güncel araştırmalarını katılımcılarla paylaştılar. İlk olarak Paderborn Üniversitesi'nden Dr. Ines Böker ve Felix Behler ortak çalışmaları olan "Nationale Identität, Repräsentationen und Transformationen von Held*innentum in der Literatur" isimli araştırmalarıyla, edebiyatta milli kimlik ve kahramanlık olgusunun temsilleri ile değişimi konusunu ele aldılar. Sunumlarına başlarken araştırmalarında karşılaştırma odaklı bir bakış açısı kullandıklarını belirten Böker ve Behler, bu incelemede kahramanlık olgusunun çağdaş dramda sosyo-politik söylemlerin tasvir şekli ve bunun kültürel çalışmalarla ilgisi üzerinde durduklarını vurguladılar. Araştırma konusunun açıklığa kavuşturulmasından sonra kültürel çalışmalar bağlamında İngiltere'de kahramanlık olgusuna değinen Behler, bu açıdan İngiltere'de kahramanlık temalı bazı anıtların temsil ettikleri değerler ve bunların kamuoyu üzerindeki etkilerinden bahsetti. Devamında bu gibi anıt betimlemelerinin onları üreten topluluklardaki asker imajının inşasındaki değişikliklerle bağlantılı olarak değişimler gösterdiğine işaret edildi. Bu değişimlerin İngiltere ve Almanya örneklerinde sosyokültürel söylemlerde ve edebi örneklerde bir yapısal değişim süreci olarak kendini gösterdiği belirtilerek, konunun bu bağlamda karşılaştırmalı bir perspektif ile incelenebilmesi için Almanya ve İngiltere'deki temel koşulları sınıflandırmanın önemi üzerinde duruldu. Bu temel koşullara örnek olarak; II. Dünya Savaşı'nda yapılan 
soykırımdan dolayı insanlığa karşı suçlu kabul edilen Alman askerinin kötü imajı sebebiyle asker mezarlarının anıtlaştııılmasının sadece çok eski zamanlardaki savaşlarda şehit olmuş askerler için söz konusu olması (en azından 2008 yılına kadar) Böker tarafından dile getirildi. Bu konunun edebiyattaki yansımasına örnek olarak ise Kriegsbraut (2011) adlı romandan bir alıntıya yer verildi. Sonrasında sözü devralan Behler, Almanya'daki benzer temel koşulların İngiltere bağlamında da geçerli olduğunu söyledi. Behler, İngiltere'deki asker imajı için 1980 yılına ait İngiltere'nin emperyalist düşünce tarzını yansıtan bir tiyatro oyunu olan The Romans in Britain adlı eseri örnek verdi. Dramaların yeni kahramanlık yapısında askerlerin temsilinin araştırılmasına yönelik yansımalar olarak değerlendirildiği sunumda, bu bağlamda Alman ve İngiliz dramlarından "savaş meydanında ölüm”, "toplum için kendini feda etme" ve "kahramanlık" temalarını işleyen örnekler konuşuldu ve bu kavramların tasvir şekillerine odaklanıldı. Sunum büyük ilgi gördü ve katılımcılardan araştırma hakkında öneri ve yorumlar geldi.

Bu oturumdaki ikinci sunumda FH Bielefeld Uygulamalı Bilimler Üniversitesi'nden Prof. Dr. Yüksel Ekinci, “Deutsch lernen anhand von Kinderliteratur. Ein mediengestütztes Projekt in internationalen Klassen" başlığını taşıyan dijital medya aracılığı ile sözcük ve dilbilgisi becerilerinin aktarımının başarı derecesinin tespit ve analizini amaçlayan projesi hakkında bilgi verdi. Çocukların gerçek çalışma örneklerine de yer verilen sunumda, çocuk kitaplarında görülen sözcüklerle yeni tümceler oluşturmanın sistematik sözcük bilgisi çalışmalarına imkân sağlaması açısından dil öğrenimine büyük katkı sunduğu üzerinde duruldu. Örnek olarak Briefe von Felix kitabından esinlenen çocukların kendi "Felix kitaplarını" oluşturmaları verildi. Son olarak bu çalışmaların çocukların psikolojilerini de olumlu yönde etkilediğine değinen Ekinci, dijital medyanın çocukların dil gelişimi üzerindeki etkisinin ana inceleme konusunu oluşturduğu araştırmada, dijital medya araçlarının dil öğrenme amacı ile kullanılmasının çocukları motive ettiği, derslere katılımı arttırdığı, çok dilliliğin önünü açtığı ve genel olarak olumlu bir etki yarattığı sonucuna varıldığını vurguladı.

Kolokyumun bir sonraki bölümünde "Junges Forum" başlığı altında doktora ve yüksek lisans öğrencilerinin çalışmalarına yer verildi. Bu bölümde ayrı bir açılış konuşması yapan Prof. Michael Hofmann genç araştırmacıların çalışmalarının çok değerli olduğunu, bu açıdan organizasyonun bu bölümü için ayrıca heyecan duyduğunu dile getirdi.

Bu oturumdaki ilk konuşmacı Paderborn Üniversitesi'nde doktora öğrencisi olan Moska Sediqi, Heinrich Böll Vakfı́ndan burs kazanan "Literarisches Lernen mit 
Fluchtliteratur" adlı doktora çalışmasını tanıttı. Doktora tezinin temel araştırma sorusunu "Fluchtliteratur kültürlerarası öğrenmeye ne ölçüde katkı sunuyor?" şeklinde ortaya koyan Sediqi, çalışmasında seçtiği edebi metinlerle edebi ve kültürlerarası öğrenmeyi desteklemek için ırkçılık ve kültür çeşitliliğine duyarlı bir Almanca dersi zemininde bir model geliştirmeyi ve geliştirilen bu modelin verimliliğini ölçmeyi hedeflediğini söyledi. Sunumun devamında sürgün edebiyatı ve 'Fluchtliteratur' arasındaki farklara değinen Sediqi, bu iki kavram arasındaki farkın netleştirilmesinin önemini vurguladı. Göçmen edebiyatının bir çeşidi olarak görülen "güncel ‘Fluchtliteratur' kavramı" ile genellikle 2015 yılından itibaren anavatanını terk ederek Avrupa'ya göç eden insanların en güncel deneyimleri kastedilmektedir. Bu edebi türün kapsamına giren eserlerin genellikle ülkelerinden kaçış sürecini betimlemeleri, anavatana karşı karmaşık hisler, kaçış sonrası travma, uyum sorunu gibi yönler içerdiğini belirten Sediqi, Abbas Khinder, Sherko Fatah, Uticha Marmon gibi isimlerin eserlerinin bu bağlamda örnek olarak verilebileceğini söyledi. Son olarak doktora çalışması çerçevesinde geliştirdiği modeli seminerlerde deneme fırsatı bulduğunu belirten Sediqi, bu proje kapsamında göçmen öğrencilerin Alman Dili ve Edebiyatı öğrencileriyle etkileşime girmelerinin önemine dikkat çekti.

Organizasyonun son sunumunda Paderborn Üniversitesi'nde yüksek lisans öğrenimlerine devam eden Melissa Haufschild ve Marco Wolfgramm, Abbas Khider'ın 'Fluchtliteratur' kategorisine ait olan Der falsche Inder (2008) adlı romanın incelediler. Sunumlarına Abbas Khinder'ın kısa bir biyografisi ile başlayan Haufschild ve Wolfgramm, sonrasında analizlerini "kaçış" teması üzerinde yoğunlaştırarak inceledikleri romanda anavatandan kaçış ile yer ve zaman kavramlarının önemini yitirmesini dikkat çekici bulduklarını dile getirdiler. Romanda sürekli gün yüzüne çıkan hareket ve yer değiştirme durumlarının okuyucuyu hem fiziksel hem de ruhsal olarak etkilediğini belirten genç araştırmacılar, kitapta hiç bitmeyen bir kaçış deneyiminin paradokslarla ve metaforlarla etkili bir şekilde betimlendiğinin altını çizdiler.

Oldukça merak uyandırıcı ve bilgilendirici bu iki sunumun sonunda verilen bir saatlik aranın ardından Marmara Üniversitesi Alman Dili ve Edebiyatı Bölüm Başkanı Prof. Dr. Leyla Coşan, Duisburg-Essen Üniversitesi'nde görev yapan psikolog ve göç araştırmacısı Prof. Dr. Hacı-Halil Uslucan ile bir röportaj gerçekleştirdi. Röportajda ağırlıklı olarak göçmenlere ayrımcılık, ırkçılık, medyanın göçmenlerin imajı üzerindeki etkisi içerikli sorular soruldu. Tüm sorulara engin bilgi ve tecrübesi ile samimi cevaplar veren Uslucan, bu konularla ilgili kendi deneyimlerini de paylaştı. Röportajın sonunda Coşan, Uslucan'a konferansın teması ile ilişkili olarak Türk-Alman sinemasının Almanya'da artık klişe olarak 
benimsenmiş Türk imajına etkisi hakkındaki düşüncelerini sordu. Öncelikle bu konu hakkında bir uzman olmadığını sadece bir gözlemci olarak cevap verebileceğini belirten Uslucan, Fatih Akın'ın filmlerinden bahsetti ve Akın'ın filmlerinde kasten klişe Türk karakterlere yer vererek bilinçli bir şekilde bu konuya odaklandığını ve bu durumun konu hakkında olumlu anlamda dikkat çeken tartışmalara yol açtığını düşündüğünü söyledi. Buna ek olarak Uslucan, olumsuz Türk imajının artık eskisi kadar yaygın olmadığını, gidilecek daha çok yol olduğunu ancak bu bağlamda büyük bir iyileşme söz konusu olduğunu belirtti. Röportajın ardından katılımcılardan gelen birkaç soruya da yanıt veren Uslucan, davet için teşekkür etti.

Kolokyumun kapanış konuşması Prof. Dr. Michael Hofmann tarafından yapıldı. Konuşmasında konferansın ana temasını oluşturan stereotiplerin ancak kültürel karşılaşmalar ve etkileşimler yoluyla ortadan kaldırılabileceğine dikkat çeken Hofmann, Alman Dili ve Edebiyatı Bölümleri Arasında İşbirliği Projesi'nin böyle etkileşimleri ve karşılaşmaları hedef aldığını ifade etti. Hofmann oldukça olumlu ve birleştirici bu mesajından sonra katılan herkese teşekkür etti ve böylece kolokyumun son oturumu da sonlandırıldı.

"Aktuelle Perspektiven der Deutsch-Türkischen und Interkulturellen Germanistik im Rahmen der Germanistischen Institutspartnerschaft Pader-Ege-Bosporus" başlıklı kolokyum, sadece Türk-Alman sineması değil, edebiyat, dilbilim, kültürel çalışmalar, bilişim ve psikoloji alanlarında da sürdürülen çalışma ve projeleri içermesi bakımından oldukça zengin içerikli bir bilimsel toplantıydı. Ayrıca genç araştırmacılar için cesaret verici, öğretici ve ilham verici bir misyona sahip olan kolokyum, yeni bilimsel çalışmalara zemin hazırlaması açısından da verimli bir etkinlikti. 
